REALA, número 12, octubre-marzo de 2019

Sección: COMUNICACIONES Y COMENTARIOS JURISPRUDENCIALES

Recibido: 08-08-2019

Modificado: 18-08-2019

Aceptado: 18-08-2019

DOI: 10.24965/reala.i12.10711

Páginas: 165-180

\title{
La STC 137/2018 de 13 de diciembre: un recordatorio sobre la constitución de sociedades mercantiles locales y una oportunidad para reflexionar sobre su gobierno
}

\author{
The Constitutional Court Judgment $n .^{\circ} 137 / 2018$ of 13 December: \\ a reminder of the constitution of local public companies and an \\ opportunity to consider its governance
}

\author{
Diego Rodríguez Cembellín \\ Universidad de Oviedo (España) \\ diegocembe@outlook.es
}

\section{NOTA BIOGRÁFICA}

Graduado en Derecho por la Universidad de Oviedo (2018). Premio fin de Grado y premio mejor expediente «Liberbank». Becario de excelencia por la Fundación María Cristina Masaveu Peterson. Actualmente cursa el Máster de Acceso al Ejercicio de la Abogacía en la Universidad Carlos III de Madrid.

\begin{abstract}
RESUMEN
EI Tribunal Constitucional ha confirmado en la STC 137/2018 la facultad que tiene el pleno del ayuntamiento de determinar el órgano encargado de asumir las funciones de junta general. Esto le ha llevado a declarar la inconstitucionalidad del artículo 14.1u) de la Ley de Capitalidad de Zaragoza que otorgaba a la junta de gobierno el papel de junta societaria en las empresas municipales. A pesar de la aparente contradicción entre la legislación básica y de desarrollo, el TC quizás se exceda en su argumentación y extiende el contenido de lo básico sin ofrecernos un razonamiento convincente. Criterios competenciales aparte, la STC 137/2018 abre un debate sobre el gobierno de las sociedades mercantiles locales y su criticada politización. Las directrices de la OCDE sobre el Gobierno de las Empresas Públicas alertan de este fenómeno y recomiendan una gestión independiente. Para ello es necesario la entrada de profesionales en los consejos de administración y la sustitución del pleno por la junta, a fin de evitar debates partidistas, en la junta de socios de las sociedades mercantiles locales.
\end{abstract}

\section{PALABRAS CLAVE}

Sociedad mercantil local; legislación básica; autonomía local; pleno; junta de gobierno.

\begin{abstract}
The Constitutional Court has confirmed in its Judgment $n .^{\circ} 137 / 2018$ the power of the city council to determine the administrative body responsible for assuming the functions of the general meeting. This made the Constitutional Court to declare the unconstitutionality of article 14.1u) of the Zaragoza Capitality Law that empowered the governing board with the role of general meeting in local companies. Despite the apparent contradiction between basic and development legislation, the Constitutional Court commits few inaccuracies in its argument and extends the content of the basics without offering convincing reasoning. Apart from competence criteria, Judgment $n .^{\circ} 137 / 2018$ opens a debate on the government of public local companies and their criticised politicization. The OECD guidelines on the Government of Public Companies warn against this phenomenon and recommend an independent management. This requires the entrance
\end{abstract}


REALA. Nueva Época - N. ${ }^{0}$ 12, octubre-marzo 2019 - ISSN: 1989-8975 - DOI: 10.24965/reala.i12.10711 - [Págs. 165-180]

La STC 137/2018 de 13 de diciembre: un recordatorio sobre la constitución de sociedades mercantiles locales y una oportunidad...

Diego Rodríguez Cembellín

of professionals in the boards of directors and the replacement of the plenary session by the government board, in order to avoid partisan debates, in the board of partners of the local public companies.

\title{
KEYWORDS
}

Local public company; basic legislation; local autonomy; city council; government board.

\begin{abstract}
SUMARIO
INTRODUCCIÓN. 1. RESUMEN Y ASPECTOS ESENCIALES DE LA STC 137/2018. 1.1. LOS PROLEGÓMENOS DE LA SENTENCIA. 1.2. LA SENTENCIA: EL JUICIO DE CONSTITUCIONALIDAD MEDIATA Y LA CREACIÓN DE SOCIEDADES MERCANTILES LOCALES. 1.2.1. El carácter básico de los preceptos de la LBRL. 1.2.2. La incompatibilidad del artículo $14.1 \mathrm{u}$ ) de la Ley de Capitalidad de Zaragoza con la LBRL. 2. APROXIMACIÓN CRÍTICA A LA STC 137/2018: UN POSIBLE EXCESO DIALÉCTICO EN LA ARGUMENTACIÓN DEL TRIBUNAL CONSTITUCIONAL. 2.1. DUDAS DESDE EL PUNTO DE VISTA JURÍDICO-PRIVADO: ¿LIMITAR ES VACIAR? 2.2. EL OLVIDADO PAPEL DEL PLENO EN LA FASE JURÍDICO-PÚBLICA DE LA SOCIEDAD MERCANTIL LOCAL. 3. DE NUEVO CON EL SISTEMA DE FUENTES LOCAL A RAÍZ DE LA STC 137/2018: LEGISLACIÓN BÁSICA, CANON DE CONSTITUCIONALIDAD E INCIDENCIA SOBRE LA CONSTITUCIONALIDAD DE OTRAS LEYES DE DESARROLLO AUTONÓMICAS. 4. EL ARTÍCULO 14.1 U) DE LA LEY DE CAPITALIDAD DE ZARAGOZA: UNA INVITACIÓN PARA LA REFLEXIÓN. 4.1. LA INEXISTENCIA DE UN DERECHO DE REPRESENTACIÓN PROPORCIONAL COMO PUNTO DE PARTIDA. 4.2. EL CRITERIO DE EFICIENCIA EN LA GESTIÓN 4.3. LA COMPOSICIÓN DEL CONSEJO DE ADMINISTRACIÓN: ¿UN ARGUMENTO DE PESO A FAVOR DEL PLENO? 4.4. LA IMPUGNACIÓN DE ACUERDOS SOCIALES: LA LEGITIMACIÓN DEL CONCEJAL NO MIEMBRO DE LA JUNTA GENERAL. REFERENCIAS BIBLIOGRÁFICAS.
\end{abstract}

\section{INTRODUCCIÓN}

La Sentencia del Tribunal Constitucional 137/2018 de 13 de diciembre constituye una oportunidad única de abordar un estudio sobre el régimen jurídico de las sociedades mercantiles locales unipersonales. El pleno de nuestro TC ha acuñado conceptos sumamente interesantes como el de «acto vacío o sin contenido», y ha descrito de forma nítida la constitución de este tipo de sociedades sobre la perspectiva del derecho mercantil. Sin embargo, no se ha acometido un estudio completo sobre este tema, ya que el TC ha obviado la fase jurídico-pública que precede a la fase jurídico-privada y se ha excedido, quizás, en los reproches efectuados sobre la Ley de Capitalidad de Zaragoza.

A su vez, analizaremos otras legislaciones autonómicas, distintas de la enjuiciada en la STC 137/2018 para ver su compatibilidad con los criterios en ella sentados. Esto nos permitirá plantearnos si el TC se ha excedido en su determinación de lo básico por lo que de nuevo se vuelve a plantear un debate interesante en el conflicto permanente de legislación básica y de desarrollo.

Ya que la Sentencia del TC versa sobre la atribución a la junta de gobierno ex lege de la representación del Ayuntamiento en la junta general de la sociedad, aprovechamos en el presente artículo para estudiar la conveniencia de esta decisión, no ya desde un plano competencial, pero sí desde la perspectiva de una gestión eficiente de los servicios públicos. Para ello tendremos en cuenta las novedades introducidas por la Ley 27/2013, de 27 de diciembre, de racionalización y sostenibilidad de la Administración Local (LRSAL), así como los apuntes doctrinales al respecto.

\section{RESUMEN Y ASPECTOS ESENCIALES DE LA STC 137/2019}

\subsection{Los prolegómenos de la Sentencia}

El 30 de noviembre de 2017 se aprobó la Ley de las Cortes de Aragón 10/2017 de régimen especial del municipio de Zaragoza como capital de Aragón, conocida como la "Ley de Capitalidad de Zaragoza". La ley no estuvo exenta de polémica, sobre todo su artículo 14.1 u) que atribuía al Gobierno de Zaragoza -junta de gobierno en los términos de la Ley 7/1985 de 2 de abril, Reguladora de las Bases del Régimen Local- «La 
REALA. Nueva Época - N. ${ }^{12}$ 12, octubre-marzo 2019 - ISSN: 1989-8975 - DOI: 10.24965/reala.i12.10711 - [Págs. 165-180]

La STC 137/2018 de 13 de diciembre: un recordatorio sobre la constitución de sociedades mercantiles locales y una oportunidad...

Diego Rodríguez Cembellín

formación de la voluntad del Ayuntamiento como socio único en las sociedades mercantiles cuyo capital social pertenezca íntegramente al municipio de Zaragoza, asumiendo las funciones de Junta General.».

Una vez que entró en vigor la ley, el Gobierno de Zaragoza decidió acabar con la proporcionalidad existente en los diversos consejos de administración de las sociedades mercantiles locales (Zaragoza Cultural, Zaragoza Vivienda, Zaragoza Deporte Municipal y Ecociudad) sustituyendo a los consejeros de la oposición por los suyos propios, decisión que provocó la reprobación del que era por entonces el alcalde, Pedro Santiesteve. Además, supuso el impulso definitivo para que el Presidente del Gobierno, que ya contaba con un dictamen del Consejo de Estado ${ }^{1}$ sobre la posible inconstitucionalidad del precepto, interpusiera un recurso de inconstitucionalidad frente al artículo $14.1 \mathrm{u}$ ) de la ley de Capitalidad de Zaragoza.

Finalmente, el pasado 13 de diciembre de 2018, el pleno del Tribunal Constitucional (TC) decidió estimar el recurso, y declarar la inconstitucionalidad del artículo 14.1 u) de la Ley de las Cortes de Aragón 10/2017, de 30 de noviembre, de régimen especial del municipio de Zaragoza como capital de Aragón.

\subsection{La Sentencia: el juicio de constitucionalidad mediata y la creación de sociedades mercantiles locales}

El controvertido artículo 14.1 u) de la Ley de Capitalidad de Zaragoza objeto del recurso de inconstitucionalidad, atribuía al Gobierno de Zaragoza el papel de junta general en las sociedades mercantiles locales. EI TC entendió que tal disposición era contraria a la regulación básica de las sociedades mercantiles locales contenida en la Ley 7/1985, de 2 de abril, de Bases del Régimen Local (LBRL), invadiendo las competencias que el artículo 149.1. 18. ${ }^{\mathrm{a}} \mathrm{CE}$ reconoce al Estado.

Al tratarse de un conflicto entre legislación básica y legislación de desarrollo, la LBRL juega un papel decisivo en cuanto a «canon de constitucionalidad» (Fernández Farreres, 2001: 408 y Parejo Alfonso, 2011: 87) de las leyes autonómicas, por lo que el primer análisis del TC en la Sentencia versa sobre el carácter básico de los preceptos de la LBRL enjuiciados. Solo previa determinación del carácter básico de los artículos en cuestión podrá el TC analizar la posible inconstitucionalidad de la legislación de desarrollo autonómica, inconstitucionalidad que en este caso será «indirecta o mediata» al no afectar directamente al articulado de la CE, pero sí al de una Ley, que por su carácter básico integra el bloque de la constitucionalidad (Álvarez García, 2013:76 y Parejo Alfonso, 2011: 87).

\subsubsection{El carácter básico de los preceptos de la LBRL}

Como señalábamos anteriormente, el TC comienza recordando que el 149.1. 18. ${ }^{a}$ CE otorga al Estado la capacidad de legislar sobre «las bases del régimen jurídico de las Administraciones públicas», título competencial que lo habilita para dictar la legislación básica sobre régimen local. Entrando en el contenido de los preceptos afectados, el TC extiende la jurisprudencia contenida en su reciente STC 41/2016, que recogía la doctrina de las STC103/2013 y STC 161/2013 en las que declaró el carácter básico de la regulación de las entidades instrumentales locales «en aquellos aspectos que son necesarios para establecer un modelo común que, en todo caso, garantice un tratamiento común a los administrados». Constituyendo la sociedad mercantil local un ente instrumental y por tanto una de las posibles formas de gestión directa de los servicios públicos (artículo 85.2 LBRL), el TC considera que los preceptos de la LBRL que la regulan, en concreto, el artículo 85ter. LBRL, tienen un carácter básico. A su vez, recuerda que la regulación de las atribuciones de un órgano del Ayuntamiento, en este caso el pleno, forma parte de la competencia básica que tiene el Estado para el desarrollo de los artículos 137 y 140 CE, configurando por tanto un «modelo de autonomía municipal común».

Declarado el carácter básico de la LBRL en lo que respecta a las sociedades mercantiles locales y a las atribuciones del pleno, procede el TC a analizar si la sustitución del pleno del Ayuntamiento en la junta general de la sociedad contraviene lo dispuesto en la LBRL y si es posible salvar tal contradicción por la vía interpretativa.

\subsubsection{La incompatibilidad del artículo 14.1 u) de la Ley de Capitalidad de Zaragoza con la LBRL}

Dos son los artículos de la LBRL que el TC menciona a la hora de analizar la posible vulneración de la legislación básica. El primero es el artículo 123.1 k) LBRL que atribuye al pleno «La determinación de las

\footnotetext{
1 Dictamen del Consejo de Estado 390/2018.
} 
REALA. Nueva Época - N. ${ }^{12}$ 12, octubre-marzo 2019 - ISSN: 1989-8975 - DOI: 10.24965/reala.i12.10711 - [Págs. 165-180]

La STC 137/2018 de 13 de diciembre: un recordatorio sobre la constitución de sociedades mercantiles locales y una oportunidad...

Diego Rodríguez Cembellín

formas de gestión de los servicios, así como el acuerdo de creación de organismos autónomos, de entidades públicas empresariales y de sociedades mercantiles para la gestión de los servicios de competencia municipal, y la aprobación de los expedientes de municipalización». El segundo, y aún si cabe más relevante, es el artículo 85ter. 3 LBRL. En el artículo 85ter. se regula el régimen jurídico de las sociedades mercantiles locales, siendo de especial interés el apartado tercero del mismo ya que recoge la designación estatutaria del órgano encargado de asumir las funciones de junta general. Dice así: «los estatutos determinarán la forma de designación y el funcionamiento de la Junta General y del Consejo de Administración, así como los máximos órganos de dirección de las mismas».

De la lectura conjunta de ambos preceptos, entendía la Abogacía del Estado que se estaba despojando al pleno de una de las competencias que le atribuía la LBRL. Sin embargo, tanto la representación de las Cortes de Aragón como la representación de la Comunidad Autónoma aragonesa, sin llegar a cuestionar el carácter básico de los preceptos, rechazaban la contradicción de los artículos 123.1 k) y 85ter.3. Esgrimían que la única de las competencias que la LBRL reservaba al pleno era la de adoptar el acuerdo de creación de la sociedad, sin que se atribuyese al mismo el ejercicio de las funciones de la junta general, u otras relativas a la manifestación de la voluntad del Ayuntamiento como pueden ser la elaboración de los estatutos.

Si bien reconoce el TC que no existe una contradicción entre la legislación aragonesa y el artículo 123.1k) LBRL, porque efectivamente lo único a lo que se refiere la legislación estatal es al «acuerdo de creación», sí que se opone frontalmente el artículo $14.1 \mathrm{u}$ ) al artículo 85.ter.3 LBRL. Para llegar a tal conclusión, el TC acuña el término de acto «vacío o sin contenido». Para el TC, bajo la ley aragonesa, el papel del pleno en la constitución de la sociedad se reduciría a adoptar un «acto abstracto», ya que le impediría decidir a este sobre uno de los aspectos esenciales a la hora de redactar los estatutos sociales, como es la designación y «el funcionamiento de la junta general y del consejo de administración, así como los máximos órganos de dirección de la misma, al configurar ex lege al Gobierno de Zaragoza como junta general de las sociedades mercantiles locales».

Sin embargo, lo que el TC ha entendido como creación o constitución de una sociedad no se reduce a eso, sino que se configura como una serie de actos perfectamente regulados en el ordenamiento jurídico privado, en concreto en el Real Decreto Legislativo 1/2010, de 2 de julio, por el que se aprueba el texto refundido de la Ley de Sociedades de Capital. Sobre esto recuerda el TC que según el artículo 85ter.1 LBRL, las sociedades mercantiles locales se regirán íntegramente por el ordenamiento jurídico privado, exceptuando las materias en las que se aplique la normativa presupuestaria, contable, de control financiero, de control de eficacia y de contratación.

La constitución por tanto se articula en tres fases distintas: (i) la voluntad del fundador, en este caso el pleno, manifestada en un acto unilateral al tratarse de una sociedad unipersonal (art. 19.1 TRLSC); (ii) la adopción de los estatutos sociales; y (iii) finalmente, el otorgamiento de la escritura de constitución en la que, entre otras cosas, debe constar los citados estatutos (art. 20 TRLSC). Crear una sociedad, competencia que la LBRL le otorga al pleno, no es «adoptar un acuerdo abstracto o vacío de contenido» señala el TC; es, en definitiva, la combinación de un acto unilateral, la adopción de unos estatutos sociales y el otorgamiento de una escritura pública de constitución. En el contenido de esos estatutos sociales es donde, por imperativo del artículo 85ter.3 debe constar quién debe ejercer las funciones de la junta general y del consejo de administración. Como señala el TC, a la hora de configurar los estatutos, el pleno podrá disponer que sea la junta de gobierno, la que asuma las funciones de junta general, pero en ningún caso se puede privar al pleno de tomar esa decisión, como sí ha hecho la ley aragonesa.

En conclusión, el TC entiende que, aunque se respete la competencia que la LBRL en su artículo $123.1 \mathrm{k}$ ) atribuye al pleno, pues en ningún momento se ha otorgado al Gobierno de Zaragoza la posibilidad de crear sociedades mercantiles locales, la contradicción con el artículo 85.ter.3 LBRL es inevitable, no siendo ni siquiera posible acudir a la vía interpretativa para «salvar» la constitucionalidad del precepto. Por lo tanto, declara inconstitucional y nulo el artículo 14.1 u) de la Ley de las Cortes de Aragón 10/2017 de régimen especial del municipio de Zaragoza como capital de Aragón.

\section{APROXIMACIÓN CRÍTICA A LA STC 137/2018: UN POSIBLE EXCESO DIALÉCTICO EN LA ARGUMENTACIÓN DEL TRIBUNAL CONSTITUCIONAL}

Dos son las cuestiones directas que podemos extraer de la STC 137/2018: la posibilidad que tiene el pleno, a través de los estatutos, de otorgar el papel de junta a otros órganos del Ayuntamiento y la interpre- 
REALA. Nueva Época - N. 12, octubre-marzo 2019 - ISSN: 1989-8975 - DOI: 10.24965/reala.i12.10711 - [Págs. 165-180]

La STC 137/2018 de 13 de diciembre: un recordatorio sobre la constitución de sociedades mercantiles locales y una oportunidad...

Diego Rodríguez Cembellín

tación sistemática de la LBRL en relación con el TRLSC para dotar de contenido a una competencia plenaria como es la creación de sociedades mercantiles locales (Oliván del Cacho, 2019: 11).

En relación con el primer punto, la contradicción del artículo 14.1 u) de la Ley de Capitalidad de Zaragoza, con el artículo 85.ter.3 LBRL es evidente y el TC ha zanjado una cuestión que en la doctrina no era pacífica. Había pronunciamientos que defendían que el pleno siempre debía de constituirse como junta cuando la sociedad mercantil estuviese íntegramente participada por el Ayuntamiento (Montoya Martín, 2011: 2.937); sin embargo, en sentido contrario se pronunciaba Rivero Ysern que abogaba por el criterio que el TC recoge en su Sentencia (Rivero Ysern, 2014: 496): la libre configuración estatutaria. En este sentido, el TC ha sido claro al afirmar que «el legislador básico estatal ha reservado al pleno municipal la facultad de optar por una u otra fórmula organizativa en las sociedades mercantiles locales, dentro naturalmente del margen de configuración dispuesto por el ordenamiento jurídico». En definitiva, la Ley de Capitalidad de Zaragoza lleva a cabo «un encargo directo al Gobierno local que este no está capacitado por el ordenamiento jurídico básico para cumplir» (Embid Irujo, 2018: 35), sin embargo, nada impide que sean los estatutos de la sociedad, previamente aprobados por el Pleno, los que le otorguen este encargo al Gobierno.

En relación con el segundo punto, es de alabar sin lugar a duda el análisis sistemático que realiza el TC en la presente sentencia. Si el Derecho no puede ser entendido como un conjunto de compartimentos estancos, menos aún lo pueden ser figuras que ya de por sí presentan una regulación mixta, en la que se combina normativa de derecho privado, como es la TRLSC, con normativa de derecho público como puede ser la LBRL.

Acierta el TC al dotar de contenido y de significado el término «creación de una sociedad mercantil» que se recoge en el artículo 123.1 LBRL donde se regulan las competencias del pleno en los municipios de gran población. Los mismos pasos que recoge el TRLSC y que el propio Tribunal recuerda: acto unilateral del socio fundador, elaboración y aprobación de estatutos y otorgamiento de la escritura de constitución, deben ser los pasos que guíen la creación de una sociedad mercantil local que por imperativo del artículo 85.ter.1 se encuentra sometida íntegramente al ordenamiento privado.

Sin embargo, el TC probablemente se ha excedido en la "crítica» a la ley aragonesa y quizás ha acuñado términos imprecisos. En este sentido, hablar de una suerte de "competencia vacía o abstracta» no parece del todo correcto por dos tipos o clases de motivos, unos directamente relacionados con la naturaleza jurídico-privada de la sociedad mercantil local, y otros con sus particularidades jurídico-públicas.

\subsection{Dudas desde el punto de vista jurídico-privado: ¿limitar es vaciar?}

En este segundo punto, y en conexión con lo anterior, vamos a abordar algunas dudas que surgen en el análisis que realiza la Sentencia sobre el proceso (jurídico-privado) de constitución de sociedades.

En primer lugar, cabe recordar que lo único de lo que se le ha privado al pleno, como socio fundador, es de la posibilidad de determinar el órgano encargado de ejercer el papel de la junta de las sociedades, e indirectamente el de designar a los miembros del consejo de administración. Los estatutos sociales, según la configuración dada por el TRLSC, al que tanto acude el TC, están sometidos a lo largo de la legislación societaria a constantes limitaciones. Por ejemplo, no serían inscribibles unos estatutos de una S. A. en la que se configurasen modos alternativos para la gestión de la sociedad (artículo 210.3 TRLSC), o en la que se estableciera un sistema de administración solidaria entre dos administradores ya que el artículo 210.2 TRLSC le impone la forma de actuación mancomunada. ¿Diríamos que el TRLSC establece unas limitaciones al socio fundador que vacían su papel al no permitirle configurar el sistema de administración de la sociedad que él desea? Probablemente no. Lo que ha hecho la Ley de Capitalidad de Zaragoza no es ni más ni menos que restringir, al igual que lo hace el TRLSC, la libre voluntad del socio fundador a la hora de configurar los estatutos de la sociedad. Sería un vaciamiento de la competencia el hecho de que fuese la junta de gobierno la que aprobase los estatutos de la sociedad porque en ese caso si que se le estaría privando al pleno de decidir sobre uno de los aspectos esenciales en la constitución de la sociedad. Esto no ocurre en el caso aragonés, ya que el artículo $11.1 \mathrm{k}$ ) de la Ley de Capitalidad reproduce el artículo $123.1 \mathrm{k}$ ) LBRL y por tanto mantiene la competencia plenaria para la «creación de sociedades mercantiles locales».

En segundo lugar, y en relación con lo anterior, al igual que destacamos el acierto del TC en su interpretación sistemática del artículo 123.1 k) con el TRLSC, la misma contiene alguna inexactitud. El Tribunal le otorga un papel preponderante al pleno a la hora de constituir la sociedad, lo que dista mucho de la realidad. Dejando de un lado la fase jurídico-pública de la que posteriormente hablaremos, es difícil imaginar que sea 
REALA. Nueva Época - N.12, octubre-marzo 2019 - ISSN: 1989-8975 - DOI: 10.24965/reala.i12.10711 - [Págs. 165-180]

La STC 137/2018 de 13 de diciembre: un recordatorio sobre la constitución de sociedades mercantiles locales y una oportunidad...

Diego Rodríguez Cembellín

el pleno como órgano colegiado el que otorgue en conjunto la escritura de constitución. Lo más sencillo y por ende lo habitual es que el pleno autorice al alcalde para que, en nombre del Ayuntamiento, sea él quien la otorgue. En definitiva, no hay duda de que «creación de una sociedad» significa lo mismo desde el punto de vista del derecho público y del privado, y es en la construcción de esa relación donde acierta el TC. Sin embargo, si no es el pleno quien en la práctica otorga la escritura de constitución (uno de los elementos esenciales en la creación de sociedades mercantiles) ni la Ley de Capitalidad de Zaragoza le ha privado de ello, sino que tan sólo se han introducido limitaciones en la redacción de los estatutos sociales (el otro elemento esencial), de modo que no parece que la competencia del artículo 123.1k) LBRL se haya vaciado.

\subsection{El olvidado papel del pleno en la fase jurídico-pública de la sociedad mercantil local}

Uno de los asuntos que el TC ha pasado por alto, quizás porque no era relevante a la hora de realizar su juicio de constitucionalidad, es la dimensión jurídico-pública que tienen las sociedades mercantiles locales. Ello presupone la existencia de una fase administrativa previa en la que el pleno juega, como veremos, un importante papel ya que deberá aprobar el expediente administrativo, lo que nos hace pensar que también aquí se ha llegado a conclusiones innecesarias y tal vez excesivas.

La existencia de un procedimiento administrativo previo no contradice el hecho de que la naturaleza jurídica de la sociedad mercantil local sea «necesariamente privada» (Santiago Iglesias, 2017: 154). Sin embargo, la sociedad mercantil local es un ente instrumental, que se subordina a dos potestades propias de los Ayuntamientos: la prestación de un servicio público y la iniciativa económica local; la sociedad mercantil local no es más que un medio de naturaleza privada al servicio de un fin de naturaleza pública.

Las bases constitucionales de uno y de otro son diferentes. Mientras que la prestación de un servicio público se relaciona directamente con aquellas competencias que tanto la LBRL como la legislación sectorial atribuyen a los Ayuntamientos en cumplimiento del principio constitucional de la autonomía local recogido en los artículos 137, 140 y 141 CE (Ortega Bernardo, 2017: 74 y García Rubio, 2015: 27), la iniciativa económica local se encuentra recogida en el artículo 128.2 CE donde se reconoce expresamente «la iniciativa pública en la actividad económica»(Rivero Ortega, 2015: 182) y está directamente relacionada con la cláusula competencial genérica que actualmente se encuentra en el artículo 7.4 LBRL por lo que no requiere una competencia propia específica para su ejercicio (Ortega Bernardo, 2017: 74). Dentro de la categoría de servicios públicos, en el ámbito local se recogen algunos que por su carácter esencial todavía pueden prestarse en régimen de monopolio, supuesto contemplado por el artículo 128.2 CE y desarrollado por la LBRL en el artículo 86.2; tales supuestos, a día de hoy, son los siguientes: abastecimiento domiciliario y depuración de aguas; recogida, tratamiento y aprovechamiento de residuos, y transporte público de viajeros.

La correcta separación e identificación de servicio público y de iniciativa económica local tiene una incidencia muy directa en el procedimiento administrativo previo, ya que el contenido de este variará en función de si nos encontramos ante la prestación de un servicio público, la prestación de un servicio en régimen de monopolio o la iniciativa económica en el mercado. En este sentido, la doctrina ha discutido sobre si de la interpretación conjunta del artículo 97.1 del Real Decreto Legislativo 781/1986, de 18 de abril, por el que se aprueba el texto refundido de las disposiciones legales vigentes en materia de Régimen Local (TRRL) y del 86.1 LBRL se excluía la tramitación del expediente para la prestación de servicios públicos ya que ambos artículos hacen mención única y exclusivamente a la iniciativa pública económica y en el caso del artículo 97.2 TRLL también a la prestación del servicio en régimen de monopolio. No recogía la legislación local la necesidad pues, de tramitar un expediente administrativo para los supuestos de prestación de un servicio público no monopolístico. (Morillo-Velarde Pérez, 2010: 1.278). Sin embargo, a pesar del tenor literal de los artículos, la mayor parte de la doctrina entendía que tras la STS de 1 de febrero de 2002 tal diferenciación carecía de efectos prácticos, ya que el Alto Tribunal estableció que en el caso de las sociedades mercantiles locales siempre se debería acudir a tal procedimiento, con independencia de la actividad o servicio público a prestar (Sosa Wagner, 2008: 45, Ballina Díaz, 2015: 89, y Montoya Martín, 2011: 2.932). Ahora bien, esta doctrina no puede ser aplicable en el contexto actual por dos motivos. En primer lugar, porque, como indica Ortega Bernardo, la STS de 1 de febrero de 2002 exigía el expediente administrativo previo para evitar la huida del derecho administrativo a través de personificaciones jurídico-privadas, y en concreto, huir de las disposiciones en materia de contratación. Sin embargo, hoy en día, y tras las sucesivas reformas de la LCSP por orden de las directivas europeas, las sociedades mercantiles locales, cuando no actúan en el mercado, es decir, cuando prestan un servicio público en sentido estricto, se categorizan como «poder adjudicador» y por tanto se encuentran sometidas a la LCSP 
REALA. Nueva Época - N. ${ }^{0}$ 12, octubre-marzo 2019 - ISSN: 1989-8975 - DOI: 10.24965/reala.i12.10711 - [Págs. 165-180]

La STC 137/2018 de 13 de diciembre: un recordatorio sobre la constitución de sociedades mercantiles locales y una oportunidad...

Diego Rodríguez Cembellín

(artículo 3.d LCSP)2. En definitiva, difícilmente se puede hablar de «huida del derecho administrativo» a la hora de prestar un servicio público si no se tiene adonde huir (Ortega Bernardo, 2017: 100). El segundo de los motivos es la reforma del artículo 85.2 LBRL operada por la LRSAL. Con anterioridad, no existía mención alguna al expediente para la gestión de un servicio público, salvo en caso de los servicios monopolísticos, sin embargo, el nuevo artículo 85.2 LBRL ya recoge la necesidad de un expediente previo, en el que se deberá acreditar, entre otras cosas que la prestación del servicio a través de la sociedad mercantil local resulta más sostenible y eficiente que la gestión a través de la propia entidad o de un organismo autónomo local basándose en criterios de rentabilidad y recuperación de la inversión. Es decir, el nuevo artículo 85.2 LBRL ha configurado un procedimiento previo y específico para la prestación de los servicios públicos locales.

La distinción principal, a efectos de la LBRL entre el expediente administrativo previo del artículo 85.2 y del contemplado en el 86.1 radica en la propia naturaleza de la actividad a desarrollar. En el caso de la iniciativa económica, al incorporarse a un mercado sujeto a las reglas de la libre competencia (del Guayo Castiella, 2014:13), no solo se tendrá que hacer un examen ad intra de sostenibilidad financiera y de estabilidad presupuestaria, sino que también se tendrá que realizar un juicio de conveniencia y oportunidad en el que se valorarán elementos ad extra Así pues, es claro el artículo 86.1 al establecer la obligación de elaborar un examen de conveniencia y oportunidad en el que se acredite que «la iniciativa no genera riesgo para la sostenibilidad financiera del conjunto de la Hacienda municipal debiendo contener un análisis del mercado, relativo a la oferta y a la demanda existente, a la rentabilidad y a los posibles efectos de la actividad local sobre la concurrencia empresarial». En el caso de los servicios públicos, al no verse la sociedad sujeta plenamente al derecho de la competencia, el examen tan solo deberá ser ad intra: sostenibilidad financiera y presupuestaria y acreditación de que la prestación del servicio público a través de una sociedad mercantil local es más sostenible y eficiente que hacerlo a través de la propia entidad local o de un organismo autónomo dependiente de la misma. (Ortega Bernardo, 2017: 97).

A pesar de los matices y pequeñas diferencias existentes entre el artículo 85.2 LBRL y el artículo 86.1 LBRL, es importante recalcar que es el pleno el que tiene la última palabra en esta fase jurídico-administrativa ya que es él el encargado de aprobar el citado expediente. Si a todo esto le sumamos que será en el propio expediente donde se deberá establecer la forma de prestación del servicio, resulta incorrecto decir que la Ley de Capitalidad de Zaragoza ha vaciado la competencia del pleno, como ha concluido el TC. Parece más adecuado señalar que ha reducido su papel al procedimiento administrativo previo, por lo que sería correcto afirmar que la Ley le ha respetado su papel en cuanto a «pleno», pero se lo ha limitado en cuanto a socio fundador de la sociedad.

\section{DE NUEVO CON EL SISTEMA DE FUENTES LOCAL A RAÍZ DE LA STC 137/2018: LEGISLACIÓN BÁSICA, CANON DE CONSTITUCIONALIDAD E INCIDENCIA SOBRE LA CONSTITUCIONALIDAD DE OTRAS LEYES DE DESARROLLO AUTONÓMICAS}

El Consejo de Estado en su dictamen, recogió tres ejemplos de «buena regulación» autonómica en contraposición con la Ley de Capitalidad de Zaragoza, en los que directamente se otorgaba al pleno las funciones de la junta general, sin posibilidad de elección en vía estatutaria. Tales ejemplos son los siguientes:

- El artículo 210 de la Ley 1/2003 de 3 de marzo de la Administración Local de la Rioja dispone que «el Pleno de la entidad asumirá las funciones de la Junta General».

- El artículo 257.1 del texto refundido de la Ley municipal y de régimen local de Cataluña dispone que «la dirección y la administración de la sociedad tienen que regirse por los órganos siguientes (...) a) la junta general, asumida por el pleno del ente local»;

- El artículo 38.4 de la Ley 5/2010, de 11 de junio, de autonomía local de Andalucía que establece que «los estatutos deberán ser aprobados por el pleno de la entidad local, que se constituirá como junta general de la sociedad».

Sin embargo, aunque el Consejo de Estado quisiera asociar pleno con junta de las sociedades mercantiles locales, tal criterio carece de validez tras la STC 137/2018. Si, como ha señalado el TC, de la lectura del

\footnotetext{
2 Recordemos al respecto que la sociedad mercantil local no tiene la condición de poder adjudicador cuando presta una actividad en el mercado, aunque pertenezca al sector público (artículo $3.1 \mathrm{~h}$ y $3.3 \mathrm{~d}$ LCSP). Sin embargo, si la duda sobre la necesidad de un expediente administrativo previo se plantea en la prestación de un servicio público, difícilmente se puede defender una huida del Derecho Administrativo al considerarse en ese punto la sociedad mercantil local poder adjudicador.
} 
REALA. Nueva Época - N.12, octubre-marzo 2019 - ISSN: 1989-8975 - DOI: 10.24965/reala.i12.10711 - [Págs. 165-180]

La STC 137/2018 de 13 de diciembre: un recordatorio sobre la constitución de sociedades mercantiles locales y una oportunidad...

Diego Rodríguez Cembellín

artículo 83.ter.3 se extrae que el pleno del Ayuntamiento puede decidir en los estatutos la forma de designación de la junta general, parece claro que la privación de tal facultad contraviene la normativa básica estatal $y$, por ende, tanto el precepto riojano, como el catalán como el andaluz serían inconstitucionales (Flores Domínguez, 2019: 66).

En efecto, lo que el TC ha entendido como inconstitucional no es que el pleno no asuma las funciones de junta en las sociedades mercantiles, sino que se haya privado al pleno de decidir tal cuestión a través de los estatutos, ya que así lo recoge la normativa estatal básica. Para ser más precisos: la LBRL no otorga al pleno en ningún caso la competencia de la junta general, sino que permite que sea él quien decida; lo que no ocurría ni en el ya inconstitucional artículo 14.1u) de la Ley de Capitalidad de Zaragoza, ni tampoco en los preceptos de la ley riojana, catalana y andaluza citados.

La constitucionalidad de los preceptos de las leyes autonómicas catalana, riojana y andaluza dependen de dos aspectos que han ido evolucionando a lo largo de la doctrina del TC: el papel de la LBRL como «canon de constitucionalidad» de la normativa autonómica y la definición del carácter básico o no del artículo 85.ter.3.

La doctrina del TC sobre el carácter de la LBRL como canon de constitucionalidad de la legislación autonómica de desarrollo no ha sido uniforme a lo largo de su historia. EI TC ha llegado a diferenciar entre el carácter básico de la legislación que concreta la garantía institucional de la autonomía local (artículos 137, 140 y 141CE) y aquella que define el régimen local o régimen jurídico de la administración local (artículo 149.1.18. ${ }^{\circ} \mathrm{CE}$ ) (Parejo Alfonso, 2015: 16) para posteriormente añadir, que «de la ley autonómica sólo podría ser canon de validez la LBRL en aquellos aspectos enraizables directamente en los arts. 137, 140 y 141 CE» (STC 159/2001 y STC 240/2006).

El tenor literal de esta jurisprudencia constitucional nos llevaría a situaciones un tanto anómalas: podría existir legislación autonómica de desarrollo que, como en el presente caso, contradiciendo la normativa básica dictada al amparo del artículo $149.1 .18 .^{\circ} \mathrm{CE}$, no sería objeto de control de constitucionalidad al no afectar a la garantía institucional de la autonomía local (artículos 137, 140 y 141 CE) y por tanto no ser la LBRL, en ese punto, y según el TC, canon de constitucionalidad. Sin embargo, tal doctrina del TC es solamente aplicable a los conflictos en defensa de la autonomía local. Dos son los motivos.

En primer lugar, en la propia STC 240/2006 el TC ha declarado que «el canon que este Tribunal deberá aplicar para resolver los conflictos en defensa de la autonomía local promovidos frente a leyes estatales se ciñe a los preceptos constitucionales (arts. 137, 140 y $141 \mathrm{CE}$ )» diferenciándolo, por tanto, de otros procedimientos constitucionales como son los declarativos de inconstitucionalidad (recurso y cuestión de inconstitucionalidad) (Parejo Alfonso, 2011: 88).

En segundo lugar, nos encontramos en la jurisprudencia más reciente del TC casos en los que a pesar de que se traten de materias relacionadas con el régimen local y por tanto con el artículo $149.1 .18 .{ }^{\circ} \mathrm{CE}$, se utiliza a la LBRL como "canon de constitucionalidad» de la ley autonómica. Un ejemplo claro es el de la Sentencia aquí comentada o el de la STC 19/2017 relativo al procedimiento de constitución de entidades inferiores al municipio en Cataluña.

En definitiva, y dejando a un lado el conflicto en defensa de la autonomía local, la LBRL siempre y cuando tenga efectivamente el carácter de ley básica, será canon de constitucionalidad de la ley autonómica (aunque no de la estatal) independientemente de que se trate de un supuesto «enraizable» en la garantía institucional de la autonomía local o en el régimen jurídico de la administración local.

Sobre el carácter básico del precepto se pronuncia de forma afirmativa el TC en la presente sentencia, recogiendo el criterio sentado en la STC 103/2013 y 143/2013 en la que se declaró la competencia estatal para regular la organización de las entidades instrumentales locales «en aquellos aspectos que son necesarios para establecer un modelo común que, en todo caso, garantice un tratamiento común a los administrados». Tal doctrina hacía referencia a la regulación de la LBRL de los organismos públicos locales y a las entidades públicas empresariales por lo que entiende el TC que es «perfectamente extensible a la gestión directa a través de sociedades mercantiles locales».

La doctrina ha llegado a tachar de «parca» (Flores Domínguez, 2019: 62) la argumentación del TC que «extiende» directamente los criterios fijados para los organismos públicos locales y las entidades públicas empresariales, entidades de derecho público, sin explicar el porqué de tal extensión. El TC debería, al menos, haber aclarado los motivos que le llevan a entender que la limitación estatutaria establecida por la Ley de Capitalidad de Zaragoza afecta a lo básico en cuanto que desdibuja el modelo común que garantice un «tratamiento común a los administrados»: ni tuvo el TC en cuenta la naturaleza jurídico-privada de las sociedades mercantiles (Flores Domínguez, 2019: 62) ni tampoco explicó cómo la mera configuración interna de las sociedades 
REALA. Nueva Época - N. ${ }^{0}$ 12, octubre-marzo 2019 - ISSN: 1989-8975 - DOI: 10.24965/reala.i12.10711 - [Págs. 165-180]

La STC 137/2018 de 13 de diciembre: un recordatorio sobre la constitución de sociedades mercantiles locales y una oportunidad...

Diego Rodríguez Cembellín

mercantiles locales puede afectar al «tratamiento común entre administrados». En este sentido, el simple hecho de que los diferentes plenos de los Ayuntamientos españoles puedan configurar diferentes modelos de junta hace que no exista un modelo único de organización de las sociedades mercantiles locales y tampoco, en consecuencia, un «modelo común» que garantice el tratamiento común a los administrados. Esta función, que, si bien legitima una regulación básica en las formas de gestión de servicios públicos, parece agotarse en establecer una normativa común aplicable (artículo 85.ter.1), unas formas societarias concretas (artículo 85.ter.2) y la existencia de unos órganos comunes en la sociedad mercantil local, así como la necesidad de elaborar unos estatutos (artículo 85.ter.1), sin que se extienda a la configuración interna de esos propios órganos.

\section{EL ARTÍCULO 14.1 U) DE LA LEY DE CAPITALIDAD DE ZARAGOZA: UNA INVITACIÓN PARA LA REFLEXIÓN}

La inconstitucionalidad del artículo $14.1 \mathrm{u}$ ) de la Ley de Capitalidad de Zaragoza no solo ofrece una enriquecedora oportunidad para el estudio de la constitución de las sociedades mercantiles locales y sus incidencias sobre la legislación básica y de desarrollo, sino que también es una invitación a reflexionar sobre el gobierno de las mismas. Si bien la contradicción entre la LBRL y la Ley de Capitalidad de Zaragoza parece evidente, esto no impide que nos sumemos al debate que la Ley de Capitalidad de Zaragoza, y, sobre todo, la actuación a posteriori del Gobierno, han puesto encima de la mesa: junta general en manos del pleno o de la junta de gobierno.

\subsection{La inexistencia de un derecho de representación proporcional como punto de partida.}

Antes de estudiar la conveniencia o no de que sea la junta de gobierno quien ostente las facultades de la junta general, debemos recordar la inexistencia de un hipotético derecho de representación proporcional en las sociedades mercantiles locales, por referencia a la ya comentada sustitución de los consejeros de la oposición.

En este sentido, cabe recordar que el TS diferencia la composición interna de los Ayuntamientos, en los que se exige el respeto al principio de proporcionalidad en conexión con el derecho al ejercicio del cargo público (artículo 23.2 CE), y los supuestos en los que el Ayuntamiento debe ser representado, en el que «voluntad se forma por el procedimiento regulado en la legislación de Régimen Local, en el que se toman las decisiones por votación mayoritaria» (STS de 1 de abril de 2004), lo que supone la negación del principio de proporcionalidad para la designación entre otros, de los representantes del Ayuntamiento en las sociedades mercantiles locales.

En definitiva, no hay ningún precepto de la LBRL que obligue a que los órganos de gobierno de las sociedades mercantiles locales reflejen la pluralidad política presente en el Ayuntamiento.

\subsection{El criterio de eficiencia en la gestión}

Precisado lo anterior, nos encontramos gracias a la STC 137/2018 ante una oportunidad única para abordar el estudio del gobierno de las sociedades mercantiles locales. Hay que recordar, que la formulación actual de la LBRL, tal y como señaló el TC en la presente Sentencia, y como había anticipado un sector de la doctrina (Rivero Ysern, 2014: 496) permite que el pleno, al configurar los estatutos de la sociedad, determine quién debe asumir las funciones de junta general, por lo que es perfectamente posible que sea la junta de gobierno quien ostente, por vía estatutaria, tal condición.

El Consejo de Estado en su dictamen ha señalado la conveniencia de una gestión por parte del pleno, entendiendo que no hay que sustraer del juego de «las mayorías y minorías» a la junta general ya que se trata de un órgano de control de gestión y financiero por lo que debe primar el principio representativo. Sin embargo, en sentido contrario ya se había en pronunciado en su día Alonso Ureba, que ha señalado cómo en legislaciones autonómicas se reserva tal facultad a órganos de naturaleza «ejecutiva» ${ }^{3}$ (Alonso

\footnotetext{
${ }^{3}$ A pesar de la fecha de la cita, los preceptos que en ella se enumeran siguen plenamente vigentes: la Ley 1/1984, de 19 de enero, reguladora de la Administración Institucional de la Comunidad de Madrid establece que «la Junta General de las sociedades mercantiles, en que la Comunidad de Madrid, sus Organismos Autónomos, Entidades de Derecho público o Entes Públicos ostenten una participación del 100 por 100 en el capital, estará constituida, respectivamente, por el Gobierno o por el Consejo de Administración del Organismo o Entidad».
} 
Ureba, 1988: 173). En el ámbito local, tenemos el claro ejemplo del Ayuntamiento de Madrid, en el que las funciones de junta general las asume la junta de gobierno ${ }^{4}$.

No podemos pasar por alto tampoco la última reforma de la LBRL operada por la LRSAL que modificó el artículo 85 LBRL para acabar con la tradicional discrecionalidad de los Ayuntamientos para elegir la forma de gestión que estimen conveniente (Alonso Mas, 2014: 480). Ahora, la nueva redacción del artículo establece que solo se podrá optar por la empresa pública empresarial o la sociedad mercantil local cuando resulte acreditado que resultan más sostenibles y más eficientes que la gestión por la propia entidad local o por un organismo autónomo local. En relación con el principio de eficiencia que indudablemente se ha introducido en la LBRL, parece más adecuado que sea la junta de gobierno la que desempeñe las funciones de junta general y no el pleno, con el mero objetivo que no se trasladen los posibles debates partidistas al órgano de gobierno de la sociedad.

En este sentido, la representación en la sociedad de economía mixta es diferente, pero debería llevarnos a la misma conclusión. Tanto en un caso como en otro, el Ayuntamiento debe ser representado como socio en la sociedad, si bien es cierto que en el caso de las sociedades de economía mixta debe concurrir con un socio privado (Santiago Iglesias, 2017: 155). A falta de regulación específica en la LBRL, operan las reglas generales de la representación (artículo 21.1.b LBRL) por lo que será el alcalde y no el pleno quién asumirá la representación del Ayuntamiento en la junta de la sociedad de economía mixta, siendo esta facultad delegable (Montoya Martín, 2011: 2.981). Lo más adecuado sería una delegación a la junta de gobierno para que así asumiese el control del conjunto de sociedades mercantiles locales, sean mixtas o unipersonales; de hecho, las Directrices de la OCDE sobre el Gobierno de las Empresas Públicas, Edición 2015 recomiendan concentrar la función de propiedad de las empresas públicas en una única entidad (Principio II.C). Lo que en ningún caso debería hacerse es de nuevo, permitir que se traduzcan las diferencias políticas en la junta de socios, máxime cuando ni siquiera, como en el caso de las sociedades de economía mixta el ayuntamiento posee la totalidad de las acciones/participaciones (Vallecillo Moreno, 2013: 6).

Por otro lado, el juego de mayorías sobre el que tanto hincapié hace el Consejo de Estado podría ser un obstáculo y un claro ejemplo de falta de eficiencia. En aquellos Ayuntamientos en los que exista una mayoría absoluta de un determinado partido político, a pesar de que eventualmente las funciones de la junta las asuma el pleno, el resultado sería el mismo que si las ostentase la junta de gobierno. Por lo tanto, nos encontraremos Ayuntamientos en los que de facto exista un control unitario, otros en los que exista de iurecomo sería el caso del Ayuntamiento de Madrid, y otros en los que no existan mayorías claras en el pleno, lo que podría condicionar e incluso torpedear al correcto funcionamiento de la sociedad mercantil local y por tanto dificultar el cumplimiento del criterio de eficiencia en la gestión que impone la LBRL.

\subsection{La composición del Consejo de Administración: ¿un argumento de peso a favor del pleno?}

Una de las competencias más importantes de la junta general de cualquier sociedad es la del nombramiento de los administradores. En este sentido, y de nuevo en relación con el criterio de la eficiencia, sería recomendable favorecer que los consejeros actúen con plena libertad e independencia. En el caso zaragozano hemos visto como la remoción de los principales consejeros de la oposición ha servido para que, entre otras cosas, se nombrase al Alcalde presidente del consejo de administración de una de las sociedades, un claro ejemplo de una mala praxis que dificulta la «eficiencia en la gestión», uno de los males recurrentes en las empresas públicas señalados por la doctrina (Laguna de Paz, 2013: 410).

Las Directrices de la OCDE sobre el Gobierno de las Empresas Públicas, van en esta línea, y hacen hincapié en la «actuación el Estado como propietario». En este sentido trazan fundamentalmente dos principios: (1) la no implicación del gobierno, entendido como entidad política, en la gestión de cotidiana de la sociedad, ciñendo su actuación a las decisiones de naturaleza estratégica y política y permitiendo que la empresa pública actúe con total autonomía (principio II.B y notas al principio II.B), (2) el ejercicio del cargo de administrador de forma «profesional e independiente (...) sin que deban guiarse por interés político alguno a la hora de cumplir con sus obligaciones como directores» (principio II.C y notas al principio II.C). La OCDE busca con sus directrices la despolitización de los órganos de gestión de las sociedades mercantiles públicas, por lo que opta por la profesionalización de los consejos de administración de estas. Por ello sería

4 Así lo dispone en el artículo 10 de los estatutos de la Empresa municipal de servicios funerarios y cementerios de Madrid S. A. y en el artículo 11 de los de Madrid Destino Turismo Cultura y Negocio S. A. 
REALA. Nueva Época - N.12, octubre-marzo 2019 - ISSN: 1989-8975 - DOI: 10.24965/reala.i12.10711 - [Págs. 165-180]

La STC 137/2018 de 13 de diciembre: un recordatorio sobre la constitución de sociedades mercantiles locales y una oportunidad...

Diego Rodríguez Cembellín

deseable que entre ellos figurasen personas ajenas a la corporación, que actuasen como consejeros no ejecutivos y que fuesen elegidos no por su afinidad política sino por su experiencia acreditada. Para la OCDE solo se debería nombrar representantes políticos o afines «únicamente si satisfacen el nivel de competencia exigido para todos los miembros del Consejo de Administración, y siempre que no sirvan de cauce a una influencia política que exceda de la función de propiedad».

La dificultad para lograr la tan ansiada independencia radica en el proceso de elección de consejeros. Si la junta de gobierno, en su papel de junta de la sociedad, es la encargada de nombrar a los administradores, esta tendría una amplia discrecionalidad a la hora de la elección de los candidatos al no tener que contar con el beneplácito de la oposición. En el caso contrario, los candidatos deberían contar con la aprobación de la mayoría del pleno, aprobación que es más sencilla de obtener si se cuenta con habilidades y experiencia acreditada que permitan un mínimo consenso entre los distintos grupos municipales. Sin embargo, se pueden articular fórmulas que, sin necesidad de que sea el pleno el que ejerza como socio único, permitan el nombramiento de candidatos independientes.

El ya citado artículo 85.ter.3 LBRL recoge que en los estatutos se determinará la «forma de designación» por lo que nada impide que, en los mismos estatutos aprobados previamente por el pleno, se establezcan criterios de selección.

Estas ideas han sido tímidamente introducidas en nuestra legislación. Tanto el artículo 288.5 del Reglamento de Obras, Actividades y Servicios de las Entidades locales de Cataluña, o el artículo 307.5 del Reglamento de Bienes, Actividades, Servicios y Obras de las Entidades Locales de Aragón, establecen que los miembros del consejo de administración deberán ser seleccionados entre personas «especialmente cualificadas». En el plano estatal, el artículo 93.1 del Reglamento de Servicios de las Corporaciones Locales (RSCL) establece que los consejeros serán designados entre «personas especialmente capacitadas por periodos no inferiores a dos ni superiores a seis años».

Se podría discutir sobre la vigencia del artículo 93.1 del RSCL, ya que el artículo 85.ter.1 LBRL hace una remisión completa al ordenamiento privado, y por tanto al TRLSC en cuyo artículo 242 se recoge la duración indefinida del cargo de administrador salvo disposición contraria en los estatutos (Montoya Martín, 2011: 2.939). Sin embargo, no parece que tal disposición afecte al requisito de «idoneidad» del administrador social derogando solo lo referente a la limitación temporal del cargo. Se podría argumentar a sensu contrario que la remisión del artículo 85.ter.1 LBRL es completa y que articula un sistema de fuentes específico para la sociedad mercantil local basado principalmente en el TRLSC y los estatutos de la sociedad, salvo aquellas materias que especialmente excepciona de su aplicación. Recordemos que el citado precepto acuña el término «íntegramente» y que el artículo 85.ter.3 encomienda a los estatutos «la forma de designación y funcionamiento de la Junta General y del Consejo de Administración» lo que conllevaría a entender derogados todos aquellos artículos del RSCL referidos al funcionamiento y composición del consejo de administración de las sociedades mercantiles locales.

Sea como fuere, lo cierto es que, tanto en un caso como en otro, nada impide que se configure esos criterios de selección a través de los estatutos, ya sea para concretar el mandato de «idoneidad» del artículo 93.1 RSCL o para recogerlo ex novo en los estatutos ya que son los encargados de recoger la «forma de designación» y además pueden contener todas aquellas condiciones que no sean contrarias a las leyes ni a los principios configuradores del tipo (artículo 28 TRLSC).

Existen otras opciones encaminadas a salvaguardar cierta independencia en los órganos de gestión como son la de reservar un número de consejeros independientes e incluso recoger un sistema de incompatibilidades que busque salvaguardar cierta independencia en los órganos de gestión. En relación a los consejeros independientes, el artículo 93.3 RSCL establece en un tercio el límite de los concejales que pueden ser miembros del consejo de administración. Sobre este artículo vuelven las dudas sobre su vigencia por los mismos argumentos anteriormente expuestos, entendiendo la doctrina que actualmente se encuentra derogado (Montoya Martín, 2011: 2.939). Si bien es cierto que reducir la presencia de representantes políticos en el consejo de administración es una medida que a los ojos de la OCDE es acertada (Nota al principio II.C), no parece que sea un remedio del todo eficaz para evitar la politización de los órganos de administración. Nada impediría que se designasen consejeros no concejales afines al partido político de turno por lo que la previsión del artículo 93.3 RSCL aparte de estar derogada, es incompleta. La idea de restringir a un tercio los concejales presentes en el consejo de administración, se podría introducir a través de los estatutos de la sociedad en cuestión, pero para su completa eficacia sería conveniente establecer una serie de criterios de selección o causas de incompatibilidad que orientasen la selección de los dos tercios restantes, o del porcentaje que se precie, ya que tal límite carece de vigencia a día de hoy. 
Un ejemplo de participación de «independientes» en la gestión de la sociedad lo constituye la Empresa Municipal de Aguas de Gijón, que prevé en sus estatutos la designación de un consejero por parte de la Federación de Asociaciones de Vecinos del municipio de Gijón en representación de los usuarios, y otros dos por las organizaciones sindicales con mayor representatividad en la comarca de Gijón, uno por cada organización. Sin embargo, estas fórmulas, de eficacia dudosa, se han articulado como instrumento para dar voz a los diferentes intereses en juego a la hora de gestionar el servicio (Ballina Díaz, 2015: 299) y no como fórmula para garantizar una gestión independiente. Convierten un órgano gestor en una confluencia de intereses diversos (laborales, de consumidores...) lo que supone ni más ni menos que trasladar los «males» que antes señalábamos para la junta de la sociedad, al consejo de administración. A mayor abundamiento, las Directrices de la OCDE sobre el Gobierno Corporativo de las Empresas Públicas critican especialmente este sistema de nombramientos ya que reclaman que los miembros de los órganos de dirección de la sociedad no actúen como representantes de una clientela y que se evite nombramientos de personas que presenten excesivos conflictos de interés (Nota al principio II.C). En el caso gijonés vemos como precisamente se nombran consejeros porque ostentan un interés muy concreto como puede ser la defensa de los usuarios 0 la de los trabajadores.

En definitiva, la independencia en el consejo de administración no depende del quién elija, o no solo al menos, sino que también y en mayor medida de los criterios en los que se basa la elección. Por tanto, la fórmula deseada para el consejo de administración sería la reserva de un número de independientes y la configuración de unos criterios de selección a través de los estatutos. Esta fórmula se adecúa al criterio de eficiencia en la gestión, podría garantizar una «cierta estabilidad» ante un hipotético cambio de signo político en el Ayuntamiento y permitiría impugnar el acuerdo de designación adoptado por la junta en caso de que se prescinda totalmente de los criterios fijados en los estatutos (artículo 204.1 TRLSC), incluso por los concejales no miembros de la junta de la sociedad, como veremos a continuación.

\subsection{La impugnación de acuerdos sociales: la legitimación del concejal no miembro de la junta general}

Un aspecto esencial a la hora de estudiar las sociedades mercantiles locales unipersonales, es abordar correctamente la naturaleza de tal sociedad. El artículo 15 TRLSC dispone que en las sociedades unipersonales el socio único ejercerá las competencias de la junta general, por lo que no debemos entender al pleno, o a cualquier órgano del Ayuntamiento al que se le confiera el papel de junta, como una junta general propiamente dicha, sino como el representante del Ayuntamiento, socio único de la sociedad. Es cierto que las sociedades locales presentan determinadas particularidades ya descritas, pero no tiene por qué primar un criterio más representativo, o democrático si se quiere, en su gestión ya que ni la ley ni la propia naturaleza jurídica de la sociedad unipersonal lo exigen.

Ahora bien, tampoco debemos entender que el pleno, y más en concreto, los concejales de la oposición queden totalmente relegados al otorgarle a la junta de gobierno el papel de junta general. Anteriormente habíamos señalado la necesidad de elaborar una memoria explicativa para constituir una sociedad mercantil local. La reforma del artículo 85 LBRL no solo introdujo los criterios de eficiencia y solvencia en la elección de la sociedad mercantil local, sino que también ha buscado que se justifiquen tales criterios. En ese sentido, en la memoria explicativa necesaria para constituir la sociedad, se deberá recoger el asesoramiento recibido, los informes sobre el coste del servicio, así como, el apoyo técnico recibido y se deberá contar con el informe favorable del interventor sobre la sostenibilidad financiera de la propuesta. Todos ello debe constar en el expediente definitivo que aprobará el pleno, sin el cual no se puede constituir la sociedad. Por lo tanto, observamos como el pleno sigue manteniendo intactas sus facultades en la fase administrativa previa a la que antes aludíamos. En definitiva, la dicotomía entre fase jurídico-pública y fase jurídico-privada debería traducirse en el mantenimiento del principio democrático y representativo a la hora de decidir sobre la prestación del servicio y la forma de prestarlo, y en la plasmación del principio de eficiencia en la gestión concreta previamente seleccionada.

Una cuestión muy relacionada con lo anterior es la relativa a la impugnación de los acuerdos sociales. El artículo 206 TRLSC establece que podrán impugnar los acuerdos sociales, además de los administradores y los socios que acrediten el porcentaje pertinente, los terceros que acrediten un interés legítimo. La pregunta que surge a continuación como no podría ser de otra forma es si tiene un concejal la legitimidad suficiente para impugnar un acuerdo de la junta de la sociedad mercantil local. Tal posibilidad ha sido rechazada por 
REALA. Nueva Época - N. 12, octubre-marzo 2019 - ISSN: 1989-8975 - DOI: 10.24965/reala.i12.10711 - [Págs. 165-180]

La STC 137/2018 de 13 de diciembre: un recordatorio sobre la constitución de sociedades mercantiles locales y una oportunidad..

Diego Rodríguez Cembellín

alguna Audiencia Provincial (SAP de las Palmas de 7 de marzo de 2008). No obstante, cabe recordar que el TC ha reconocido una legitimación ex lege en el acceso a la jurisdicción-contencioso administrativa de los concejales, distinta de la que otorga con carácter general el artículo 63.1 LBRL, para aquellos supuestos en los que no se puede votar en contra del acuerdo por no pertenecer al órgano competente (STC 173/2004 y STC 108/2006). Tal legitimación no la planteó el tribunal en un mero «interés abstracto en defensa de la legalidad» sino en un interés muy concreto, e incluso obligación que tiene el concejal como cargo representativo de controlar el correcto funcionamiento del Ayuntamiento. ¿Se podría aplicar tal criterio a la impugnación de acuerdos sociales? Es más ¿debería incidir la condición de empresa pública a la hora de apreciar el interés legítimo en la impugnación de acuerdos sociales? En la doctrina existen pronunciamientos favorables al respecto (Ballina Díaz, 2014: 19) que nos parecen correctos ya que si analizamos la jurisprudencia del TC podríamos llegar a la misma conclusión. En primer lugar, el TC aprecia la imposibilidad del concejal de participar en la votación del acuerdo, supuesto que sucedería en el caso de que la junta de gobierno actuase como junta general, y en segundo lugar apela a una legitimación ex lege por el deber que le asiste como cargo electo, de controlar el correcto funcionamiento del Ayuntamiento. ¿Acaso el hecho de que se actúe a través de una sociedad mercantil exime al concejal de tal obligación? Probablemente no.

El principal argumento que se podría esgrimir para no considerar aplicable la doctrina recogida en la STC 173/2004 es la naturaleza jurídica de los acuerdos adoptados por la junta de las sociedades mercantiles locales. Efectivamente y tal como indica la doctrina, no son actos administrativos, (Sosa Wagner: 2008, Ballina Díaz, 2014: 158) por lo que no son recurribles en la vía contencioso-administrativa. Sin embargo, si bien es cierto que estos acuerdos son «materialmente mercantiles» también lo es que procedimentalmente están sujetos al Derecho Administrativo. Es decir, el órgano que actúe como junta de la sociedad estará sometido a las normas administrativas relativas a la adopción de acuerdos (Montoya Martín, 2011: 2.937). Esto es así debido a que, como hemos señalado anteriormente y pese a que el artículo 85.ter.1 realiza una remisión íntegra al ordenamiento privado, el pleno o la junta de gobierno no son una junta de socios a la que concurran diversos socios y en el que opere el juego de mayorías recogido en el TRLSC. Recordemos que las sociedades mercantiles locales íntegramente participadas son unipersonales, lo que significa que tan solo existe la voluntad del socio único por lo que no operan, por cuestiones obvias, las mayorías mínimas requeridas en el TRLSC. Lo que hace el pleno o la junta de gobierno es expresar la voluntad del socio único que es el Ayuntamiento y para expresar tal voluntad están sujetos, como no puede ser de otra manera, a la normativa administrativa. Si entendiésemos que el régimen de adopción de acuerdos es el del TRLSC le otorgaríamos a los concejales el papel de socios, lo que es del todo incongruente con una sociedad unipersonal -al existir varios socios- y con el papel del pleno o de la junta de gobierno, como socio único. Tal interpretación viene reforzada por lo dispuesto en el artículo 92.1 RSCL en el que se dispone que «el funcionamiento de la Corporación constituida en Junta general de la Empresa se acomodará, en cuanto al procedimiento y a la adopción de acuerdos, a los preceptos de la Ley y del Reglamento de Organización, funcionamiento y régimen jurídico de las Corporaciones locales, aplicándose las normas reguladoras del régimen de las Sociedades anónimas en las restantes cuestiones sociales». Aunque de nuevo podríamos cuestionarnos la vigencia de este precepto por lo expuesto anteriormente, lo cierto es que en este caso no entra en contradicción directa con el TRLSC como ocurre con otros supuestos, por lo que podría considerarse plenamente aplicable (Ballina Díaz, 2014: 168). En este caso, a pesar de que exista una remisión íntegra al derecho privado en el artículo 85.ter.1 LBRL, el artículo 92.1 RSCL no está regulando una cuestión mercantil porque en las sociedades unipersonales realmente no existe como tal una junta de socios (Coscullela Montaner, López Benítez, 2009: 145), sino que como indica el artículo 15 TRLSC «el socio único ejerce las funciones de la junta general».

Fruto de lo anterior, la doctrina y la jurisprudencia han construido lo que se conoce como la teoría de los «actos separables» (Flores Domínguez, 2019: 55 y Ballina Díaz, 2014: 167) a efectos de la impugnación de los acuerdos que adopte el órgano encargado de asumir las funciones de la junta general en las sociedades mercantiles locales. Por ello, las cuestiones relacionadas con el régimen de adopción de acuerdos, como pueden ser los quórums necesarios, el régimen de mayorías o el régimen de abstención en la votación, están sometidas necesariamente a derecho público y por tanto deberán ser impugnadas en su caso antes la jurisdicción contencioso-administrativa (Ballina Díaz, 2014). Por el contrario, el contenido material de tales acuerdos sí que tiene naturaleza mercantil y por aplicación de la doctrina de los actos separables son impugnables ante los juzgados de lo mercantil.

En relación a esto, y volviendo con la cuestión de la impugnación de acuerdos de la junta general de la sociedad por los concejales no miembros, se produciría una paradoja de difícil explicación lógica. Si se pro- 
REALA. Nueva Época - N.12, octubre-marzo 2019 - ISSN: 1989-8975 - DOI: 10.24965/reala.i12.10711 - [Págs. 165-180]

La STC 137/2018 de 13 de diciembre: un recordatorio sobre la constitución de sociedades mercantiles locales y una oportunidad...

Diego Rodríguez Cembellín

duce una infracción del régimen de adopción de acuerdos, aquel concejal que no hubiera participado en la votación por no ser miembro de la junta de la sociedad, en el caso de que no se confiase al pleno, podría impugnarlo ya que el mismo vulneraría normas de derecho público y por tanto estaría plenamente legitimado si atendemos a la jurisprudencia del TC ya citada. Ahora bien, si la ilegalidad del acuerdo reside en el contenido de este, y por tanto son de aplicación las reglas societarias sobre impugnación de acuerdos sociales (artículo 204 TRLSC) el concejal no miembro no podría impugnar el acuerdo, salvo que la doctrina del TC se traslade también a otros órdenes jurisdiccionales, como aquí defendemos, al menos para este caso concreto.

Si bien es cierto que el control de lo formal es importante, las cuestiones más relevantes en cuanto al correcto funcionamiento de la sociedad son de índole material. Si el TC reconoció la legitimidad basándose en una hipotética obligación que tiene el concejal de velar por el correcto funcionamiento del Ayuntamiento, tal obligación juega un papel más importante en el control de las actuaciones materiales que es donde se podrían producir los mayores perjuicios para la sociedad mercantil local. A mayor abundamiento, tampoco la legislación mercantil parece excluir del todo esta legitimidad. En este sentido, el interés que exige el TRLSC no tiene porqué ser patrimonial (Baena Banea, 2016:145) sino que puede ser suficiente una mera afectación a sus derechos, por lo que entronca perfectamente con el cometido que la jurisprudencia del TC les ha otorgado a los concejales.

En conclusión, si antes hablábamos de que el pleno mantendría competencias importantes en el plano jurídico-público, ahora señalamos que los concejales que lo integran podrían mantener, en el caso de que se le otorgase a la junta de gobierno el papel de junta de la sociedad, un mínimo control de la actuación de la sociedad en el ámbito privado, siempre y cuando se acepte por los tribunales la interpretación aquí expuesta. Esto reforzaría, aún más, la idea de trasladar tal función (la de junta de la sociedad) a la junta de gobierno y no al pleno. De hecho, podría ser un instrumento esencial para controlar el nombramiento de administradores sociales que no cumplan con los requisitos de «idoneidad» que se deberían incluir en los estatutos a la hora de configurar el consejo de administración.

\section{A MODO DE CONCLUSIÓN}

La primera y más importante conclusión que debemos extraer de la STC 137/2018 de 13 de diciembre es la facultad que tiene el pleno de determinar a través de los estatutos de la sociedad mercantil local el órgano encargado de asumir las funciones de la junta general. Así pues, el artículo 14.1 u) de la Ley de Capitalidad de Zaragoza privaba al pleno de la elección, imponiendo ex lege, a la junta de gobierno local como representante del Ayuntamiento en las sociedades mercantiles locales.

La contradicción entre el artículo 14.1u) de la ley aragonesa y el artículo 85.ter.3 LBRL era evidente y desemboca en la inconstitucionalidad del precepto, sin embargo, el TC no justifica de forma convincente el carácter básico del artículo 85.ter.3. El TC señala al respecto que el Estado tiene competencia en la regulación de los entes instrumentales locales «en aquellos aspectos que son necesarios para establecer un modelo común que, en todo caso, garantice un tratamiento común a los administrados» por lo que entiende que la regulación de la sociedad mercantil local del artículo 85.ter.3 enjuiciada tiene tal carácter. Sin embargo, el TC no lo ha llegado a aclarar cómo se garantiza un tratamiento común a los administrados si lo que precisamente permite la LBRL es la libre configuración de los órganos societarios. Entender como básica la regulación del funcionamiento interno de la sociedad mercantil local estrecha sin duda el margen competencial de las CCAA en este punto, aunque hemos visto como no sólo ha sido Aragón la que ha legislado sobre la materia en sentido contrario a lo dispuesto en el artículo 85.ter.3.

Por otro lado, el TC puede que se haya excedido en sus críticas a la Ley de Capitalidad de Zaragoza. Si bien el término «acto vacío o sin contenido» es del todo ilustrativo, no parece que sea aquí aplicable. El artículo $14.1 \mathrm{u}$ ) no ha vaciado ninguna competencia «esencial» del pleno a la hora de constituir una sociedad, tan solo ha impuesto límites, tal y como hacen otras leyes de nuestro ordenamiento jurídico, a la libre configuración de los estatutos sociales. A su vez, el TC ha olvidado el preponderante papel que la LBRL le otorga al pleno en la gestión de los servicios públicos y en la iniciativa económica local porque es él y no otro, quién decide las cuestiones mas trascendentales en estos aspectos.

Dejando a un lado los aspectos constitucionales, la STC 37/2018 abrió la puerta a un debate sobre el régimen de gobierno corporativo de las sociedades municipales. Hoy en día, en la mayoría de las sociedades locales los concejales del ayuntamiento se «quitan el sombrero de político» y se ponen el de "accionista» (Vallecillo Moreno, 2013: 6) lo que provoca en muchos casos una falta de eficacia y eficiencia en la gestión. 
REALA. Nueva Época - N. ${ }^{0}$ 12, octubre-marzo 2019 - ISSN: 1989-8975 - DOI: 10.24965/reala.i12.10711 - [Págs. 165-180]

La STC 137/2018 de 13 de diciembre: un recordatorio sobre la constitución de sociedades mercantiles locales y una oportunidad...

Diego Rodríguez Cembellín

Trasladar los debates políticos al ámbito societario no parece lo más conveniente a la hora de gestionar un servicio público o prestar una actividad económica. Por tanto, hemos propuesto que sea la junta de gobierno la que asuma las funciones de junta general y que se determine en los estatutos de la sociedad criterios de selección o de capacidad a la hora de seleccionar a los integrantes del consejo de administración.

Finalmente, y a efectos de no desplazar por completo a los concejales de la oposición, se debería reconocer jurisprudencial o legalmente su legitimidad a la hora de impugnar aquellos acuerdos societarios que consideren que atentan contra el interés social que no deja de ser, al encontrarnos ante un ente instrumental, el interés de la Corporación.

\section{REFERENCIAS BIBLIOGRÁFICAS}

ALONSO MAS, M. J. (2014): "El nuevo régimen de los instrumentos de intervención de las entidades locales", en DOMINGO ZABALLOS, M. J. (coord.): Reforma del Régimen Local: la Ley de Racionalización y Sostenibilidad de la Administración Local: veintitrés estudios, págs. 439-476. Navarra: Thomson Reuters Aranzadi.

ALONSO UREBA, A. (1988): La sociedad mercantil de capital como forma de la empresa pública local. Madrid: Universidad Complutense, Facultad de Derecho, Sección Publicaciones.

ÁLVAREZ GARCÍA, V. (2013): "Las reglas constitucionales sobre la interiorización del régimen local en los estatutos de autonomía de segunda generación y la problemática naturaleza jurídica de la ley reguladora de las bases de régimen local", en Revista Española de Derecho Constitucional, núm. 99, págs. 61-97. Disponible en: http://www. cepc.gob.es/publicaciones/revistas/revistaselectronicas? IDR=6\&IDN=1316\&IDA=36865.

BAENA BAENA, P. J. (2016): "El nuevo régimen jurídico español de la legitimación activa y pasiva para la impugnación de acuerdos de las sociedades de capital", en Revista de Derecho, núm. 20, págs. 125-160 (consultado 13-072019). Disponible en: http://revistasnicaragua.net.ni/index.php/revderecho/issue/view/255.

BALLINA DÍAZ, D. (2014): "Reclamaciones frente a las actuaciones de las sociedades mercantiles de capital íntegramente municipal: jurisdicción competente y legitimación de los concejales para su impugnación”, en Revista de Estudios de la Administración Local y Autonómica REALA, núm. 2, págs. 155-176 (consultado 10-072019). DOI: https://doi.org/10.24965/reala.v0i2.10194.

BALLINA DÍAZ, D. (2015): Las sociedades mercantiles de capital íntegramente municipal: instrumentos públicos entre el Derecho Público y el Derecho Privado. Madrid: Instituto Nacional de Administración Pública INAP.

COSCULLELA MONTANER, L. y LÓPEZ BENÍTEZ, M. (2009): Derecho Público Económico. Madrid: lustel.

EMBID IRUJO, A. (2019): "Informe general sobre el Gobierno Local en 2018”, en Anuario Aragonés del Gobierno Local 2018, núm. 10, págs. 15-43 (consultado 15-07-2019). Disponible en: https://ifc.dpz.es/publicaciones/ver/id/3762.

FERNÁNDEZ FARRERES, G. (2001): "Artículo 28" en REQUEJO PAJÉS, J. L. (coord.): Comentarios a la Ley Orgánica del Tribunal Constitucional. Madrid: Tribunal Constitucional y Boletín Oficial del Estado. Disponible en: https://www.tribunalconstitucional.es/es/publicaciones/Publicaciones/Coedicion-LOTC.pdf.

FLORES DOMÍNGUEZ, L. E. (2019): "La junta general en las sociedades mercantiles locales", en Revista de Estudios Locales CUNAL, núm. 219, págs. 48-67.

GARCÍA RUBIO, F. (2015): “La iniciativa económica local tras la ley 27/2013, de 27 de diciembre, de racionalización y sostenibilidad de la administración local", en Revista de Estudios de la Administración Local y Autonómica REALA, núm. 3, págs. 9-33 (consultado 15-07-2019). DOI: https://doi.org/10.24965/reala.v0i3.10238.

DEL GUAYO CASTIELLA, I. (2014): "Nuevo régimen jurídico de los servicios públicos locales, tras la Ley núm. 27/2013, de 27 de diciembre, de racionalización y sostenibilidad de la Administración Local”, en Revista de Estudios de la Administración Local y Autonómica REALA, núm. 2, págs. 9-25 (consultado 24-07-2019). DOI: https://doi.org/10.24965/reala.v0i2.10190.

LAGUNA DE PAZ, J. C. (2013): Derecho Administrativo Económico. Madrid: Civitas.

MONTOYA MARTÍN, E. (2011): "La gestión de los servicios locales a través de empresas municipales y mixtas", en MUÑOZ MACHADO, S. (dir): Tratado de Derecho Municipal, vol. IV, págs. 2.921-2.985. Madrid: lustel.

MORILLO-VELARDE PÉREZ, J. I. (2010): "La gestión de los servicios de las entidades locales", en COBO OLVERA, T. (dir): Tratado de Derecho Local, págs. 1.267-1.302. Navarra: Thomson Reuters Aranzadi.

OLIVÁN DEL CACHO, J. (2019): "La inconstitucionalidad de la atribución a la junta de gobierno local de las funciones de junta general de las sociedades municipales. A propósito de la STC 137/2018, de 13 de diciembre”, en Boletín Digital Contencioso, núm. 30, págs. 2-14 (consultado 24-07-2019). Disponible en: http://www.ajfv.es/wpcontent/ uploads/2019/04/Boletin-CONTENCIOSO-Abril-2019.pdf.

ORTEGA BERNARDO, J. (2018): "Servicios públicos e iniciativa económica local" en VELASCO CABALLERO, F. (dir): Tratado de Derecho Económico Local, págs. 73-104. Madrid: Marcial Pons.

PAREJO ALFONSO, L. (2015): "Las bases del régimen local en la doctrina del Tribunal Constitucional", en Cuadernos de Derecho Local QDL, núm. 37, págs. 12-40 (consultado 16-07-2019). Disponible en: https:// repositorio.gobiernolocal.es/xm/ui/bitstream/handle/10873/1646/Parejo_Bases_regimen_local_p_12_40. pdf? sequence=1\&isAllowed=y. 
REALA. Nueva Época - N. ${ }^{12}$, octubre-marzo 2019 - ISSN: 1989-8975 - DOI: 10.24965/reala.i12.10711 - [Págs. 165-180]

La STC 137/2018 de 13 de diciembre: un recordatorio sobre la constitución de sociedades mercantiles locales y una oportunidad...

Diego Rodríguez Cembellín

PAREJO ALFONSO, L. (2011): "La autonomía local en la Constitución Española” en MUÑOZ MACHADO, S. (dir): Tratado de Derecho Municipal, vol. IV, págs. 48-210. Madrid: lustel.

RIVERO ORTEGA, R. (2015): Derecho Administrativo Económico. Madrid: Marcial Pons.

RIVERO YSERN, J. L. (2014): Manual de Derecho Local. Navarra: Thomson Reuters Aranzadi.

SANTIAGO IGLESIAS, D. (2017): "Empresas locales" en VELASCO CABALLERO, F. (dir): Tratado de Derecho Económico Local, págs. 153-192. Madrid: Marcial Pons.

SOSA WÁGNER, F. (2008): La gestión de los servicios públicos locales. Navarra: Thomson Reuters Aranzadi.

VALLECILLO MORENO, F. (2013): "Retrato de una empresa pública que no huye del derecho administrativo", en Diario la Ley, núm. 8.107 (consultado 25-07-2019). 